\title{
Novel pollen analogue technique shows bumblebees display low floral constancy and prefer sites with high floral diversity
}

\author{
Angélica Elizabeth Martínez-Bauer (D) - Fergus J. Chadwick (D) - Aaron J. Westmoreland (i) • \\ Tonya A. Lander (i)
}

Received: 12 February 2021 / Accepted: 8 July 2021 / Published online: 30 July 2021

(C) The Author(s) 2021

\begin{abstract}
Context There have been dramatic global declines in pollinating insects. A common land management intervention to support wild pollinators is to plant non-crop flowering plants ('pollinator planting'). However, there are limited data on which species or spatial arrangement of planting provide maximum benefit to wild pollinators.

Objectives Here we investigate which flowering species and locations are visited by free-foraging Bombus terrestris (buff-tailed bumblebees) in speciesrich semi-natural grassland and woodland.

Methods Two study nests of buff-tailed bumblebees were established in Wytham Woods, UK. Pollen analogue pigments were sprayed on open flowers in
\end{abstract}

Supplementary Information The online version contains supplementary material available at https://doi.org/10.1007/ s10980-021-01304-9.

A. E. Martínez-Bauer · A. J. Westmoreland .

T. A. Lander $(\bowtie)$

Department of Plant Sciences, University of Oxford,

South Parks Road, Oxford OX1 3RB, UK

e-mail: tonya.lander@plants.ox.ac.uk

Present Address:

A. E. Martínez-Bauer

Grupo Agroecología, Departamento de Agricultura,

Sociedad Y Ambiente, El Colegio de La Frontera Sur,

Carretera Panamericana Y Periférico Sur S/N Barrio

María Auxiliadora, CP 29290 San Cristóbal de Las Casas,

Chiapas, Mexico the study area over a period of two months, with unique colours used to identify separate sections of the study area. Pollen load analysis was used to identify forage species and foraging locations.

Results Bumblebees showed low flower constancy, visiting five flower species per trip on average, and as a group the sampled bumblebees visited 36 of the 49 plant species identified in study area surveys. Many individuals foraged in multiple, spatially-discrete locations during single trips.

Conclusions The positive relationship between floral diversity and pollen load species diversity, and the positive relationship between site floral diversity and frequency of visitation, suggest behavioural strategies that maximize the diversity of flower species visited, in line with the energetic costs and benefits hypothesis. This supports recommendations for pollinator plantings with high species diversity, potentially spread across many small forage areas across the landscape.

\section{F. J. Chadwick}

Institute of Biodiversity, Animal Health and Comparative Medicine, University of Glasgow, Graham Kerr Building, Glasgow G12 8QQ, UK

Present Address:

A. J. Westmoreland

Department of Ecology and Evolutionary Biology,

University of Colorado, 1900 Pleasant St, Boulder,

CO 80302, USA 
Keywords Pollinator planting · buff-tailed bumblebee (Bombus terrestris audax) · Flower constancy - UV fluorescent pollen analogue pigment . Pollinator foraging - UK Countryside Stewardship Options

\section{Introduction}

Dramatic global declines in pollinator species (Potts et al. 2010; Díaz et al. 2019; Powney et al. 2019) threaten ecosystem function (Ollerton et al. 2011) and human food security (Klein et al. 2003). One of the most common land management interventions to support wild pollinators, and attempt to mitigate pollinator decline, is to increase flowering plant diversity and abundance through 'pollinator planting' in both urban and agricultural environments (Gemmill-Herren et al. 2021). Choice of flower species and spatial distribution of sites is thought to affect foraging efficiency (see Wolf et al. 1975; Pyke 1980), and therefore fitness (Hixon 1982). However, guidance on what type of floral resources should be provided is limited (Dicks et al. 2015), and knowledge of how providing small, spatially discrete, floral resource patches may impact foraging behaviour and success is inadequate (Chittka et al. 1999; Ebeling et al. 2008). Although, in general, planting more flower species over more area is likely to support a greater diversity and abundance of pollinators (Ebeling et al. 2008; Nielsen et al. 2012; Blaauw and Isaacs 2014), both space and funds are limited, so we need to know which and how many floral resources to provide, and where to put them, to better support pollinators through planting. To begin to address those broad questions of what and where to plant, we ask the more specific questions:

(Question 1) Which, and how many, flowering plant species are visited by free-flying bumblebees in a floristically diverse, semi-natural meadow and woodland landscape?

(Question 2) Does the number of flowering plant species present in a patch impact the frequency of pollinator visits to the patch, or the number of patches a pollinator visits during a foraging bout?

We use floral constancy theory to develop predictions about, and behavioural explanations for, the diversity of flower species a pollinator visits (Question 1), the probability of visiting high vs. low floral diversity sites, and the probability of visiting multiple foraging sites during a foraging bout (Question 2). Floral constancy is defined as the pattern of foraging wherein an individual pollinator visits a restricted number of flower species, even when other equally rewarding species are available, and if the insect has no innate or imprinted predisposition to visit only flowers of a restricted plant taxon (Raine et al. 2006). Something like a floral constancy pattern may arise because the pollinator has an innate physiological requirement for a particular reward from a specific plant taxa, termed 'fixed preference' (Waser 1986), or through optimal foraging, where the most rewarding flowers are sufficiently abundant and superior that the highest reward-intake rate is achieved by skipping inferior flowers (Waddington and Holden 1979), termed 'labile preference' (Waser 1986). In this manuscript we use the term floral constancy as defined above, distinct from either fixed or labile preference as defined by Waser (1986) (see broader reviews of floral constancy in Amaya-Márquez 2009; Grüter and Ratnieks 2011).

Hypotheses to explain floral constancy behaviour largely relate to the energetic costs of flower handling and travel, opportunity costs of missed rewards, and the costs of information acquisition; essentially the costs related to foraging efficiency (see Wolf et al. 1975; Pyke 1980; Hixon 1982). Because the bumblebees in this study were not naïve foragers, we do not make behavioural predictions related to learning processes or the costs of information acquisition [e.g. the interference hypothesis (Chittka et al. 1999; Gegear and Laverty 2005; Amaya-Márquez 2009; ), the learning investment hypothesis (Amaya-Márquez 2009; Grüter and Ratnieks 2011), or the majoringminoring hypothesis (Heinrich 1976a; Chittka et al. 1997)]. Rather, in this study we focus on hypotheses related to the energetic costs of flower handling, travel, and missed rewards; specifically, the energetic costs and benefits hypothesis, the costly information hypothesis, and the passive constancy/inconstancy concept.

During an individual foraging bout, the energetic costs and benefits hypothesis (Grüter and Ratnieks 2011), which is linked to optimal foraging theory (e.g. Waddington and Holden 1979), suggests that floral constancy should be lower in locations with high flower diversity and high reward value per flower, or 
when flowers are spaced farther apart, because of the greater cost to bypass an encountered flower (Gegear and Thomson 2004; Goulson 1999). The same foraging pattern, inconstancy in areas of high floristic diversity, could also be explained by passive behaviour, where travel is costly and experienced foragers simply forage on whatever flower species are locally present (Heinrich 1976b), we term this 'passive inconstancy' (see 'passive constancy', Heinrich 1976b; Thompson 1983). Under the energetic costs and benefits hypothesis, as well as in the passive inconstancy foraging scenario, the costly-information hypothesis suggests that if rewards are small, pollinators will actively search for alternative floral resources (Grüter and Ratnieks 2011), which may result in leaving the patch (Chittka et al. 1997). This response has been shown empirically in honeybees, bumblebees and hoverflies (Goulson 1999). These three hypotheses together suggest that pollinators should use a wide range of flowers in areas of high plant diversity, and not actively search for alternative floral resource locations as long as the available species offer sufficiently valuable rewards (Raine et al. 2006). Based on these hypotheses, we predict the following for our study:

Question 1, Prediction: Foragers in the sites with high floral diversity will display lower floral constancy (visit more flower species) than foragers in low floral diversity sites.

Question 2, Prediction 1: Pollinators will preferentially visit the sites with the highest floral diversity.

Question 2, Prediction 2: Foraging trips that include the highest floral diversity sites will include fewer foraging stops (fewer spatially discrete foraging locations) than foraging trips that do not include the highest floral diversity sites.

To address these questions and predictions we developed a simple and inexpensive pollen analogue technique which, in combination with pollen load species analysis, allowed us to identify both the sites and species an individual pollinator visited during a given foraging bout.

\section{Materials and methods}

Study site

Wytham Woods is a 390 ha ancient semi-natural woodland to the west of Oxford, UK $(51.77 \mathrm{~N},-1.34 \mathrm{~W})$. In July 2015, two commercially-produced nests of British buff-tailed bumblebees (Bombus terrestris audax; http://www. biobestgroup.com) were located in two semi-natural calcareous meadows, Quarry Meadow (Q) and South Meadow (S), hereafter called the 'home meadows' and Quarry Meadow Nest (QN) and South Meadow Nest (SN) (Fig. 1). Quarry Meadow is surrounded by ancient semi-natural woodland and South Meadow is bordered on three sides by ancient semi-natural woodland and on the fourth side by the Grazed Sheep Pasture (G). The nests were $121 \mathrm{~m}$ apart, and approximately equally distant from two species-rich wildflower meadows, Singing Way Road (R), 272 m to QN and $192 \mathrm{~m}$ to SN, and Upper Seeds Meadow (U), $242 \mathrm{~m}$ to QN and $250 \mathrm{~m}$ to $\mathrm{SN}$, and from the Grazed Sheep Pasture (G), $179 \mathrm{~m}$ to QN and $114 \mathrm{~m}$ to SN (Fig. 1, Table 1). All spatial analyses were undertaken in ArcMap 10.4.1 (ESRI, Redlands, USA).

\section{Pollen load analysis}

To address Question 1: Which, and how many, flowering plant species are visited by free-flying bumblebees under natural conditions?, the entrance holes of both bumblebee nests, QN and SN, were modified to create a trap mechanism that allowed a single forager bee returning to the nest to be collected (Figure S1). Bees were collected between 9:00 and 16:00 h on 14, 15, 16, 25, 29, and 30 July, 5, 12, 17, 19, 20, 26, and 27 August and 2, 3 September 2015. These were days with temperatures $>13{ }^{\circ} \mathrm{C}$ and at least $60 \%$ clear sky, or $>17{ }^{\circ} \mathrm{C}$ in any sky conditions, with no collections if raining (following Pollard and Yates 1993). Collected bees were cooled at $4{ }^{\circ} \mathrm{C}$ for $2-3 \mathrm{~min}$ and then placed in a marking cage (www.thorne.co. uk). Clean tissue paper was placed over the sponge plunger to avoid cross-contamination between samples. Pollen from both corbiculae was removed using a pin and stored at $4{ }^{\circ} \mathrm{C}$. Because $B$. terrestris shows size polymorphism, and bumblebee size has been found to affect foraging behaviour (Spaethe and Weidenmüller 2002), and the diversity of pollen 


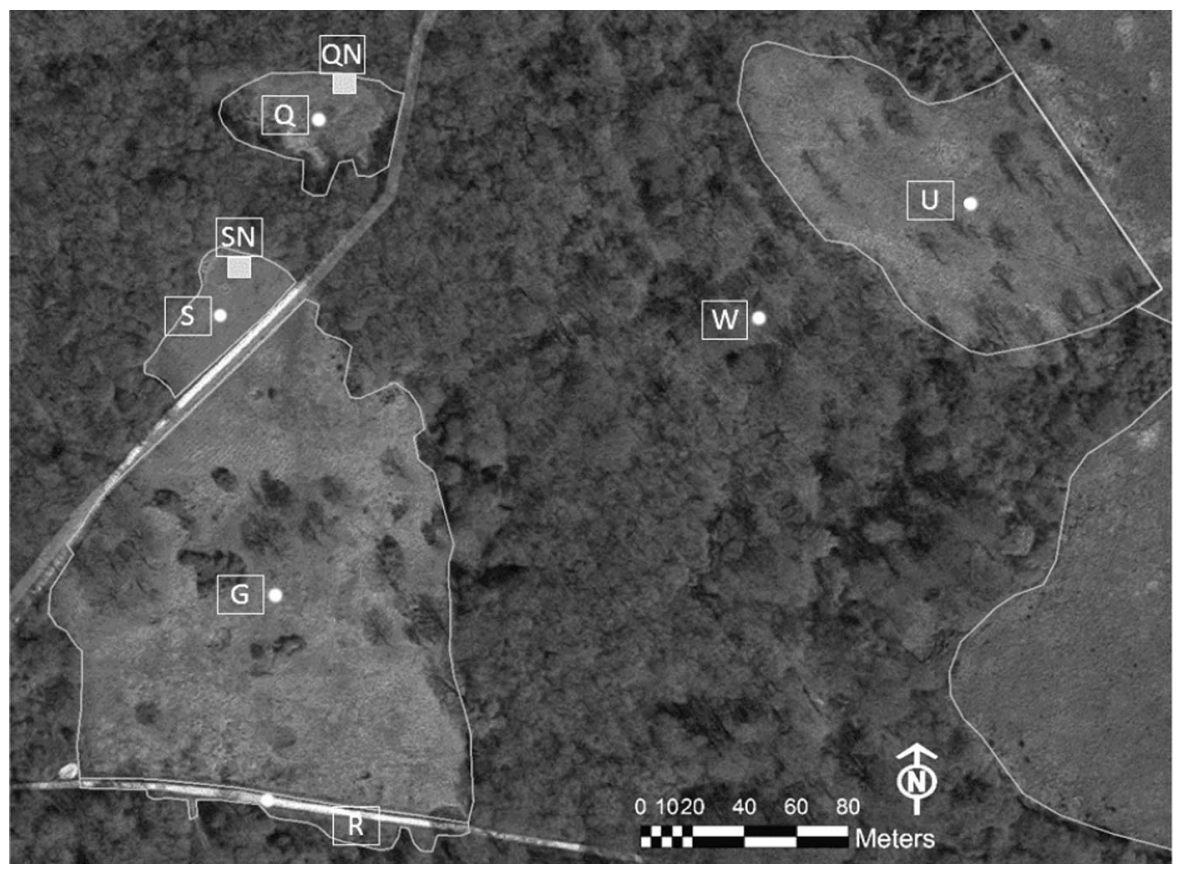

Fig. 1 The study area in Wytham Woods. Latitude/longitude data corresponds to the geometric centroid of each polygon, shown above as a white point in the centre of each polygon. The abbreviation for each sample area is shown on the map surrounded by a white rectangle for clarity: QN Quarry Meadow
Nest, $S N$ South Meadow Nest, $Q$ Quarry Meadow (51.771, - 1.338), S South Meadow (51.770, - 1.339), G Grazed Sheep Pasture $(51.769,-1.339), W$ Woodland $(51.770,-1.336)$, $U$ flower-rich Upper Seeds Meadow (51.770, - 1.335), $R$ flower-rich Singing Way Road $(51.769,-1.339)$

Table 1 Flowering plant data and number of foraging visits for the six areas surveyed in 2015

\begin{tabular}{lllr}
\hline & Total flowering plant species & Area of the polygon (ha) & Number of recorded visits (home meadow) \\
\hline Grazed Sheep Pasture (G) & 6 & 2.17 & 22 \\
Woodland (W) & 8 & 9.96 & 0 \\
South Meadow (S) & 19 & 0.13 & $83(74)$ \\
Quarry Meadow (Q) & 23 & 0.20 & 56 \\
Singing Way Road (R) & 25 & 0.18 & 53 \\
Upper Seeds Meadow (U) & 28 & 5.44 & $85)$
\end{tabular}

The 'home meadow' value indicates the number of visits to the meadow that were from the experimental bumblebee nest located within that meadow

species in pollen loads (Gervais et al. 2020), intertegular distance (ITD) of each bee was measured with a digital calliper and used as a proxy for individual size (Cane 1987). One researcher collected all of the ITD measurements.

The species in each pollen load were analysed by taking a slice down the centre, along the long axis, of one pollen load from each bee sampled. This approach ensured that each layer of pollen added during foraging was included in the subsample to be identified. The subsample was homogenized in $70 \% \mathrm{EtOH}$, allowed to dry, and fixed in glycerol jelly. One in three slides (70 total) were inspected completely at $400 \mathrm{X}$ (10X ocular $\times 40 \mathrm{X}$ objective) magnification on a Zeiss compound light microscope, and all pollen grains present were identified to the lowest taxonomic level possible. One hundred and thirty slides were inspected using four evenly spaced transects across the 
slide, and all pollen grains present on the transects were identified to the lowest taxonomic level possible. Pollen was identified using the pollen library (see 'Flowering plant diversity' section below) and Sawyer's (1981) guide. One researcher conducted all of the pollen identifications, which were then checked by a second researcher.

\section{Flowering plant diversity}

To address Question 2: Does the number of flowering plant species present in a patch impact the number of flower species the pollinator visits, or the frequency of pollinator visits to the patch?, data on plant species presence and abundance was collected in the six study patches (Fig. 1). Vegetation surveys were conducted on 29 July and 12 August 2015 by walking northsouth transects separated by $3 \mathrm{~m}$ across the whole of each of the six study areas. All flowering plants were identified to species and their abundance in the combined transects in each sample area were recorded on a DAFOR scale [Dominant (60-100\% cover in the combined transects), Abundant (30-59\%), Frequent (10-29\%), Occasional (5-9\%), Rare (<5\%)] (Pescott et al. 2019) (Table S1). In the study areas grasses were always the dominant species in terms of ground cover, but, as they are not expected to be important pollen plants for bumblebees, they were excluded from the plant surveys. Thus, no plant received a 'Dominant' score in the vegetation survey data (Table S1). Pollen samples from all flowering species were collected during the vegetation surveys and added to a pollen library for use in identification of pollen loads. All surveys were undertaken by the same researcher.

UV fluorescent pigment as a pollen analogue to identify foraging locations

For Question 2 we also needed to know which, and how many, different foraging locations individual foragers visited before returning to the nest. To achieve this, we developed a new technique based on the use of ultraviolet fluorescent pigment powder as a pollen analogue (UVPs).

Systematic comparisons of pigment and pollen movement have shown that pigment does not affect pollinator behaviour or survival (Klaus et al. 2015), and that pigment and pollen movement are correlated (Adler and Irwin 2006; but see Van Rossum et al.
2011). UVPs provide an inexpensive pollen analogue that is observable with both traditional and fluorescence microscopes (Thomson et al. 1986). However, the extent to which treating flowers with UV fluorescent pigment affects pollinator foraging behaviour has not been extensively investigated. Therefore, flight cage experiments were conducted to compare bumblebee foraging preference between six colours of UV fluorescent pigment (Radiant Color, Series Radglo GWT) on dry pollen pellets (Agralan, UK, http:// www.agralan.co.uk), plus unpigmented pollen pellets (control) (21 separate tests; Table S2). These pigments are fully visible for humans, as well as being UV fluorescent. For all tests, three feeding stations of each treatment colour or control were placed in an alternating pattern in a flight cage $(230 \times 360 \times 190 \mathrm{~cm})$ (Fig. 2). Feeding stations consisted of a lid from a $1.5 \mathrm{ml}$ Eppendorf tube containing $0.2 \mathrm{ml}$ of $50 \%$ sucrose solution glued onto a $5 \mathrm{~cm}$ diameter plastic lid containing one $1.5 \mathrm{ml}$ Eppendorf tube-full of pollen pellets. Prior to the experiment, the bumblebees were kept in a closed nest and fed only sucrose solution and pollen pellets. For each observation session, three naïve Bombus terrestris audax (Agralan, UK), were released into the flight cage. The bumblebees were allowed to settle for $30 \mathrm{~min}$ and then observed for $30 \mathrm{~s}$ every $5 \mathrm{~min}$ for $30 \mathrm{~min}$. During observation each bumblebee was counted as 'flying', 'resting', 'drinking nectar' (if the tongue was extended into the nectar), or 'on pollen' (if the antennae were actively exploring the pollen), and the colour of the pollen where the bee was drinking or exploring the pollen was recorded.

The flight cage experiment found blue-pigmented pollen was visited more frequently than control, and control and yellow-pigmented pollen were visited more frequently than pink-pigmented pollen, but there were otherwise no significant differences between colours (Table S3). These results are in line with a previous study that showed no difference in dispersal patterns among pigment colours (Van Rossum et al. 2011). In our field study we therefore used Orange, Red, Green and Blue pigments, between which we found no significant difference in bumblebee preference. The pigments were tested for distinctness from each other by comparing them when mounted in glycerol jelly and viewed under the microscope. All pigments were found to retain full colour after a week 


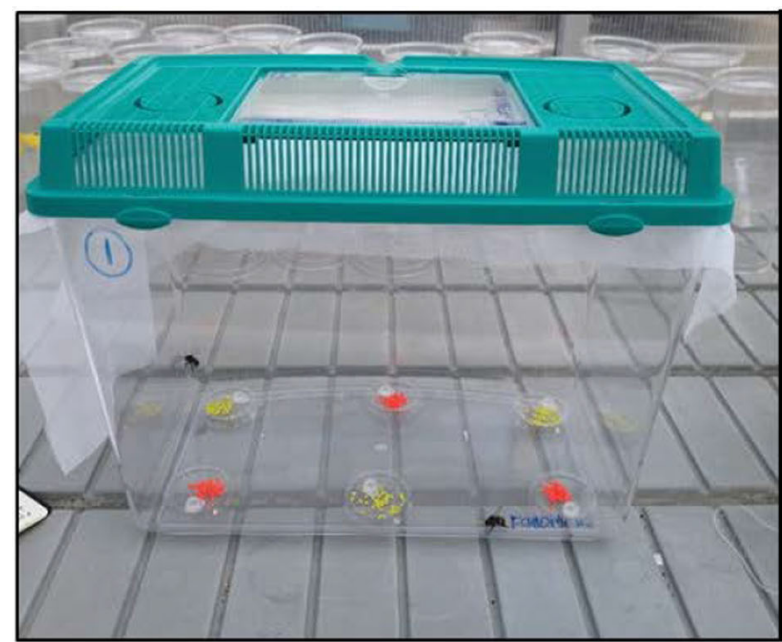

Fig. 2 Experimental flight cage for the pigment preference trials. In this experiment, after the bumblebees had settled for $30 \mathrm{~min}$, they were observed for $30 \mathrm{~s}$ every $5 \mathrm{~min}$ for $30 \mathrm{~min}$. In the cartoon on the right, bumblebee 1 would be counted as

exposed to weather and sunlight on an open flower in the field.

Foraging location identification

Based on the flight cage tests, four colours (red, orange, green, and blue) of fluorescent powder pigment were applied to all open flowers in four regions of the study area. A separate atomizer was used to apply each colour. The atomizers are designed for even application of dry powder onto a surface, and consist of a $1.5 \mathrm{oz}$ glass jar with a metal lid and nozzle, and a rubber squeeze bulb which is used to spray powder out of the nozzle (http://www.naimies.com/ atomizer.html). All open flowers in Q were pigmented red, $\mathrm{S}$ was green, $\mathrm{G}$ was blue, and $\mathrm{R}$ was orange. Pigment was not applied if there were high winds or when it was raining. Pigment was applied at all sites on 5, 12, 17, 19, 20, 26, 27 August and 2, 3 September 2015, and pollen loads were collected from bees, as described above, on those same days. Note, some pollen loads were collected in July, prior to the start of flower pigmenting, but once pigmenting began, pollen loads were only collected on the days pigments were applied. Bees collected the pigment along with pollen and stored it in their corbiculae, and the presence of coloured pigment particles was noted during pollen load analysis (Thomson et al. 1986; Kearns and Inouye 1993).

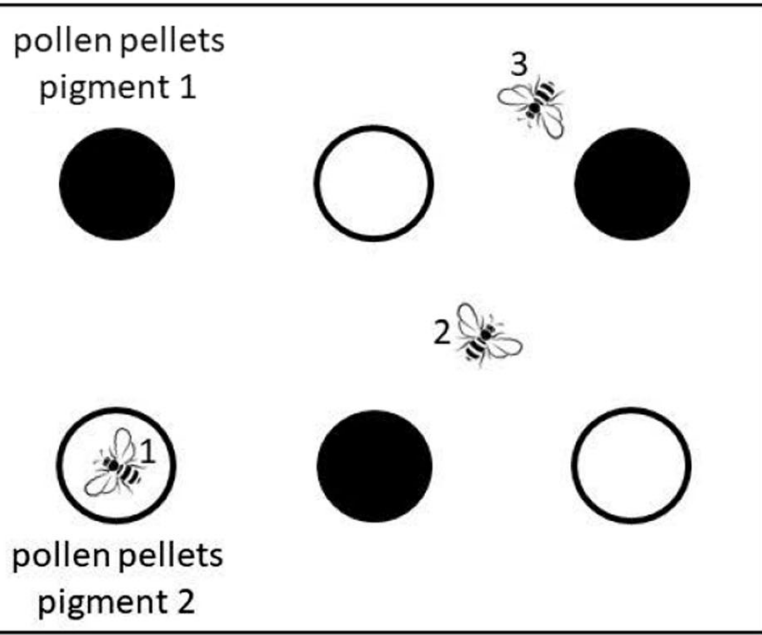

'drinking nectar' (if the tongue was extended into the nectar), or 'on pollen' (if the antennae were actively exploring the pollen), and the colour of the pollen (pigment 2) would be recorded. Bumblebees 2 and 3 would be counted as 'flying' or 'resting'

The pollen load analysis revealed that $\sim 24 \%$ of pollen loads collected after August 5, when pigmenting began, contained UVPs. It is not unexpected that not all pollen loads will contain UVPs. Studies of pollen analogue carry-over between foraging locations (the traditional use for pollen analogue pigments) find exponential decay in the presence of pigment on recipient flowers, with low pigment deposition values at $4-50 \mathrm{~m}$ from the pigment source (Thomson et al. 1986; Van Rossum et al. 2011). Therefore, our finding that $24 \%$ of pollen loads contained pigment may be a result of pigment deposition during flower visits, loss of pigments during grooming, uneven distribution of pigment in the bee's pollen loads such that our pollen load sampling method did not always capture collected pigments, or some combination of those mechanisms. Additionally, the bumblebees may have foraged beyond the area where the pigmenting experiment was implemented. However Bombus terrestris are expected to forage a maximum of $750 \mathrm{~m}$ from their nest site (Goulson 2009), and $750 \mathrm{~m}$ to the north, and south of the experimental nests was closed canopy woodland with little forage available, and to the west was closed canopy woodland and an agricultural field producing grain. To the east, beyond Upper Seeds meadow and more than $750 \mathrm{~m}$ distant, was a field used for sheep grazing which may have provided some forage; however, we expect that the majority of 
foraging occurred in the area to the east/south-east of the nests where pigment was applied.

Because not all pollen loads contained UVPs, we combined the UVP data with data on the presence of pollen from flower species only present in single locations in the study area to identify foraging locations. Twenty-two of the 49 flower species were found at only one survey site during either July or August or both (Table S1). Of these twenty-two, five are common species [recorded in more than $65 \%$ of the $10 \mathrm{~km}$ grid squares across the whole of the UK (Proctor 2013; Botanical Society of Britain and Ireland et al. Accessed October 2020)]: Circaea lutetiana, Convolvulus arvensis, Potentilla reptans, Prunella vulgaris, and Taraxacum officinale; and one, Euphrasia nemorosa, is present in $53 \%$ of the UK $10 \mathrm{~km}$ grid squares and more than $80 \%$ of UK broadleaved woodlands (Kirby et al. 2005). Thus, although these species were found only rarely during the plant surveys, their presence was not used to identify foraging locations. The other single-location species were used to identify foraging locations in the study area (following Beil et al. 2008).

\section{Statistical analyses}

We approached flower constancy from two perspectives: linear modelling and network analysis. The aim of Model 1 (see below) was to quantify to what extent the number and identity of foraging sites, as well as the days from the start of the season (a proxy for seasonal change), and thorax width (a proxy for individual bumblebee size), influenced the number of pollen species identified in the pollen loads. Model 2 (see below) tested the relationship between flowering plant diversity at a foraging site and how frequently a site was visited. The network analysis was intended to test individual bee-plant interactions against a null model of random interactions to detect constancy. All statistical analyses were done in R 3.2.2 (R Core Team 2017) and the $R$ codes are available as Appendix 1.

To address Question 1, we fit a model to determine what predictors led to higher species richness in individual pollen loads. Based on our stated Prediction, we expect coefficients associated with visitation to species rich areas ( $\mathrm{S}, \mathrm{Q}, \mathrm{R}$, and $\mathrm{U})$ to be positive, suggesting higher pollen diversity and thus lower flower constancy at the individual level. Model 1 (pollen species number), a generalized linear model with a Poisson distribution (glmulti, Calcagno and de Mazancourt 2010), was used to assess the ability of explanatory variables 2-12 (Table 2) plus 'Nest' (either $\mathrm{SN}$ or $\mathrm{QN}$ ) as a fixed effect, to predict the response variable, total number of pollen species in a given pollen load (FNP). All pairwise interactions between explanatory variables were included. The package's genetic algorithm was used to automate model selection by identifying the model with the lowest AIC. We then performed a Likelihood Ratio Test (LRT), using R's drop1function to identify terms to drop and the ANOVA function (with a Chi-square test), to determine if any terms could be dropped from the lowest AIC model (for discussion of this approach see Johnson and Omland 2004; Calcagno and de Mazancourt 2010). We tested for overdispersion of our Poisson model with the dispersiontest function from the AER package (Kleiber and Zeileis 2008). Marginal effects of significant terms were plotted

Table 2 Model 1 (pollen species number), the linear model to assess the relationship between flower constancy and foraging location, started with number of pollen species in a pollen load (FNP, variable 1), a measure of floral constancy, as a function of variables 2-12 and their interactions, plus 'Nest' (either SN or QN) as a fixed effect

Model 2 (flowering plant richness), the linear model to assess the relationship between the number of visits to a site and the number of flowering plant species at that site, started with number of visits to a site (VG-VU (variables 4-8), as a function of variables 9 and 13. All possible pairwise interactions between the factors in Models 1 and 2, but no higher order interactions, were considered

\begin{tabular}{lll}
\hline Variable & Description \\
\hline 1 & FNP & Number of pollen species \\
2 & DFS & Days from start of study \\
3 & TW & Thorax width \\
4 & VG & Visitation to pasture G \\
5 & VQ & Visitation to meadow Q \\
6 & VR & Visitation to road R \\
7 & VS & Visitation to meadow S \\
8 & VU & Visitation to meadow U \\
9 & Num.Stops & Number of foraging stops \\
10 & OneStop & One stop in the foraging trip \\
11 & HMO & Foraging in home meadow only \\
12 & After.Bloom & Foraging after thistle bloom in meadow G \\
13 & NFP & Number of flowering plants \\
\hline
\end{tabular}


using the ggeffects package (Lüdecke 2018), via the sjPlot package (Lüdecke 2018). We used Student's t-tests to assess possible biases introduced by the presence of pollen analogue colours.

To address Prediction 1 for Question 2: bees will preferentially forage in areas where species richness is higher (S, Q, R, and U), and Prediction 2 for Question 2: foraging trips that include the highest floral diversity sites will include fewer total foraging sites, we fit Model 2 (flowering plant richness) ( $\mathrm{R}$ code section 'Visitation vs Richness GLM-replacement for correlation'). Model 2 was a generalized linear model with a Poisson distribution used to assess the ability of flowering plant richness at each site (variable 13 in Table 2), to predict the response variable: number of visits to a site [VG-VU (variables 4-8, Table 2)]. We expected a positive relationship between site species richness and number of visits per site, and a negative relationship between site species richness and the number of foraging stops.

For network analysis, we constructed bipartite networks using the $\mathrm{R}$ packages vegan (Oksanen et al. 2017), bipartite (Dormann et al. 2008), and igraph (Csardi and Nepusz 2006) (see R script for details of data conversion to interaction matrix). We then calculated d' (Blüthgen et al. 2006) for each individual bee. d', which is based on Shannon entropy, was originally proposed for species level interactions, to measure specialization within communities. Here we apply it to individual level interactions, to detect specialization at the level of individual foragers. At the network level, $d$ ' measures the 'uniqueness' of nodes relative to the lower level of the network. If these nodes represent species, highly unique nodes would indicate interaction frequencies or strengths that are very different from the abundances of available resources. d' compares observed visitation to a 'null' where visits are randomly distributed and thus correspond closely to abundances for resource species. When applied to the individual level, it contains the same information, but now describes specialization of individual foragers. In the generalized linear model above, Model 1, increased species richness in pollen loads may indicate decreasing flower constancy, but the approach does not control for abundance or evenness of the plant species in the foraging location. The d' analysis complements Model 1 by describing the degree to which individual bees may be showing 'preference' for particular plant species by determining whether pollen species are present in the same abundances in the pollen load as the plant species are in the field. Departure of pollen abundances from floral abundances gives an indication of individual foraging preference.

For this analysis we used floral abundance data from the plant surveys as the measure of plant species abundance, not the default value of marginal totals from the interaction network. The d' metric ranges from 0 to 1 , where 0 indicates random visits among the resource plants and 1 indicates complete specialization relative to the available plant species. The assumptions of our analysis are, first, because we are using individual foraging bouts from individual bees as data points to assess foraging constancy, we are assuming that each foraging bout is representative for that individual bee. Second, because all study areas needed to be included in the network, but only one abundance value could be assigned to each flowering plant species, the abundance values were the average values for the combined data from the six study areas. There were two plant species, Rhinanthus minor and Pinus silvestris, that were present in pollen loads but not in the plant surveys. We chose to exclude Pinus as its presence in pollen loads is most likely to be an artefact of Pinus pollen contamination on other species' flowers. We included Rhinanthus as 'Rare,' setting its abundance to 0.01 at a single site. The decision to consider it as 'Rare' within our study sites rather than artefacts of further flung foraging trips is arbitrary and may impact our understanding of foraging, particularly for lower-frequency species. We used a one-sample $t$-test to determine whether the overall distribution of d' was significantly different from zero, which would represent no specialization. We acknowledge that because we don't have multiple foraging bouts per individual, the $t$-test results are a signal test rather than a formal hypothesis test.

\section{Results}

Pollen load analysis

Of 200 pollen load samples analysed, only 16 contained just one pollen species (see Tables S4, S5). The mean number of species per pollen load was 5 and the range was $1-17(\mathrm{SD}=2.70)$. The total number of species identified in all pollen loads combined was 
37. This included 35 of the 49 species identified in the plant surveys, plus two species not seen in the plant surveys (Tables S1, S4, S5). The species not seen in the plant surveys were Rhinanthus minor (Orobanchaceae) and Pinus silvestris (Pinaceae). Rhinanthus minor is a rare hemi-parasite of species in the Poaceae and Fabaceae which, given its rarity, may have been missed in the transect surveys. Pinus silvestris is present in small quantities across Wytham Woods, and its wind-borne pollen could have contaminated any of the flowers in our study area. Overall, these data show both that individuals visited a large number of species on individual foraging bouts, and that the majority of available non-grass flowering plant species were visited.

\section{Flowering plant diversity}

The 'home meadows', $\mathrm{S}$ and $\mathrm{Q}$, and the two wildflower meadows, $\mathrm{R}$ and $\mathrm{U}$, showed higher flowering plant diversity (19-28 species), whereas woodland $(\mathrm{W})$ and pasture $(\mathrm{G})$ showed lower flowering plant diversity (6-8 species) (Tables $1, \mathrm{~S} 1)$. Pairwise Sorenson's Beta Dissimilarity Index $\left(\beta_{\mathrm{SOR}}\right)$ was used to evaluate flower species turnover and nestedness between the foraging sites using the $\mathrm{R}$ package betapart (Baselga and Orme 2012). For $\beta_{\text {SOR }}$, values closer to 1 indicate greater dissimilarity between sites. $\beta_{\text {SOR }}$ estimates were higher in pairs involving one low diversity site (W or $\mathrm{G}$ ) and one high diversity site (Q, $\mathrm{S}, \mathrm{R}$, or U), compared to when they involved two high diversity sites (Table S6). This is a common pattern for Beta diversity estimates along species richness gradients. However, $\beta_{\mathrm{SOR}}$ was also high for the pair involving two low diversity sites. If we decompose $\beta_{\text {SOR }}$ into its component parts of dissimilarity derived from species turnover $\left(\beta_{\text {SIM }}\right)$ and dissimilarity derived from nestedness $\left(\beta_{\mathrm{SNE}}\right)$, we find that $\beta_{\mathrm{SNE}}$ values are highest for pairs involving either $\mathrm{W}$ or $\mathrm{G}$, suggesting that the species found at the lower diversity $\mathrm{W}$ and $\mathrm{G}$ sites are largely a subset of the species found at the other four sites, but they are largely not the same subset of species (based on the high $\beta_{\text {SOR }}$ value for the $\mathrm{W}+\mathrm{G}$ pair). Moreover, we find that $\beta_{\mathrm{SNE}}$ values are high for pairs involving the higher diversity Q, R, S, and $U$, suggesting that there are important differences in species identity between these sites (Table S6).
UV fluorescent pigment as a pollen analogue to identify foraging locations

Model 1 started with number of pollen species in a pollen load (FNP, Table 2) as a function of 11 variables (Table 2) and their pairwise interactions. Variables were removed using glmulti's genetic algorithm based on AIC. The final model was then tested using LRTs to determine whether any variables could be dropped without worsening fit. The final model with the lowest AIC included days from the start of the study (DFS), thorax width (TW), and visitation to $\mathrm{S}, \mathrm{Q}, \mathrm{U}$, and $\mathrm{R}$, plus interactions between thorax width (TW) and visitation to $S$ and $U$, as well as an interaction between visitation to $\mathrm{S}$ and $\mathrm{Q}$. Coefficient estimates, standard error, and $\mathrm{p}$ values are presented in Table 3. Marginal effect plots for all terms and interactions are shown in Fig. 3. The number of stops on a foraging trip was dropped from the final model, suggesting there was no significant impact of the number of stops on the number of pollen species in a pollen load, or any significant interaction between the number of stops and the identity of foraging location. A Likelihood Ratio Test (LRT) demonstrated that the interaction between $\mathrm{S}$ and $\mathrm{Q}$ could be dropped without worsening model fit, and so the final model does not include it. No other parameters could be dropped without worsening model fit based on subsequent LRTs (Table 3, Residual deviance: 137.5 on 171 degrees of freedom). The final model was not overdispersed $(\mathrm{z}=-3.0975$, $p=0.99)$, but was underdispersed $(p=0.0009)$. We used a Chi-Square test on the residual deviance of the model to assess goodness of fit. Here the null hypothesis is that our model is correctly specified, and so failure to reject indicates a good fit for our model. We found a strong fit between model and data $(p=0.97$, df $=171)$. See associated R script (Appendix 1) for more information on model fitting and selection.

In support of the Prediction for Question 1, Model 1 coefficients for visitation to $\mathrm{Q}$ and $\mathrm{R}$ were both positive, indicating pollen loads from flights including these sites with high flowering plant diversity were likely to have higher pollen diversity. DFS had a negative coefficient, suggesting pollen load diversity decreased with progression through the flowering season. Thorax width was only significant as part of pairwise interactions with visitation to $S$ and $U$, an 
Table 3 Final model summary for Models 1 and 2 (Table 2)

\begin{tabular}{|c|c|c|c|c|c|}
\hline Variable & & Coefficient estimate & Std error & $\mathrm{Z}$ value & $\mathrm{P}$ value \\
\hline \multicolumn{6}{|l|}{ Model 1} \\
\hline (Intercept) & & 2.124 & 0.661 & 3.212 & $0.001 *$ \\
\hline DFS & Days from start of study & -0.007 & 0.003 & -2.485 & $0.012 *$ \\
\hline TW & Thorax width & -0.175 & 0.118 & -1.485 & 0.137 \\
\hline VQ & Visitation to meadow $\mathrm{Q}$ & 0.449 & 0.098 & 4.567 & $0.000 *$ \\
\hline VR & Visitation to singing way road $\mathrm{R}$ & 0.345 & 0.074 & 4.691 & $0.000 *$ \\
\hline VS & Visitation to meadow $\mathrm{S}$ & -1.387 & 0.757 & -1.832 & $0.067 *$ \\
\hline VU & Visitation to Upper Seeds meadow U & 2.333 & 0.781 & 2.985 & $0.003 *$ \\
\hline VS:TW & & 0.374 & 0.146 & 2.572 & $0.010^{*}$ \\
\hline VU:TW & & -0.355 & 0.152 & -2.340 & $0.019 *$ \\
\hline \multicolumn{6}{|l|}{ Model 2} \\
\hline (Intercept) & & 2.633 & 0.197 & 13.525 & $0.000 *$ \\
\hline NFP & Number of flowering plants & 0.063 & 0.0084 & 7.524 & $0.000 *$ \\
\hline
\end{tabular}

*Indicates a $\mathrm{P}$ value of $<0.05$
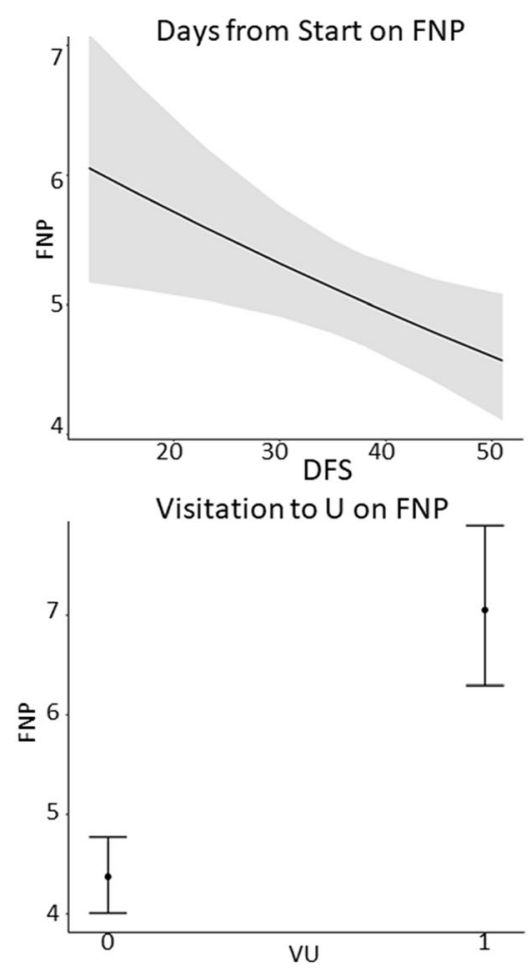

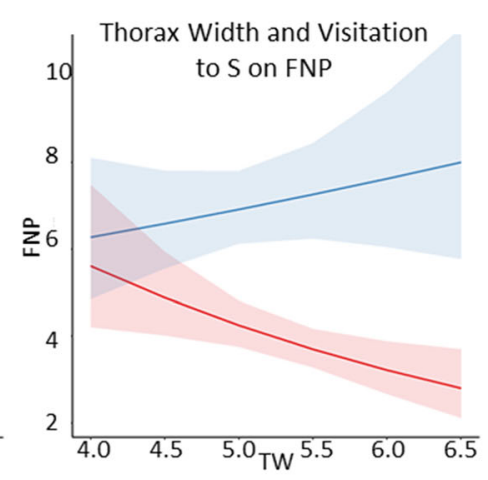

Visitation to $\mathrm{R}$ on FNP

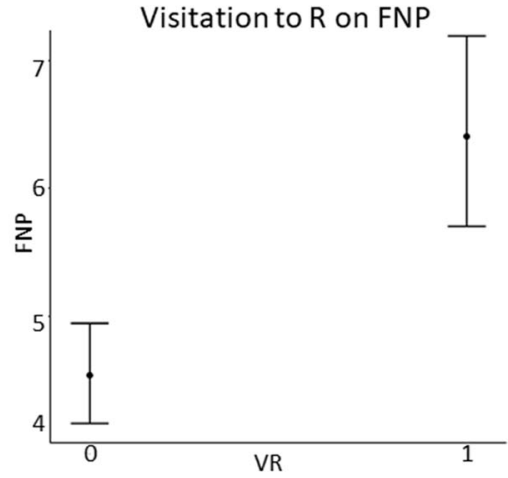

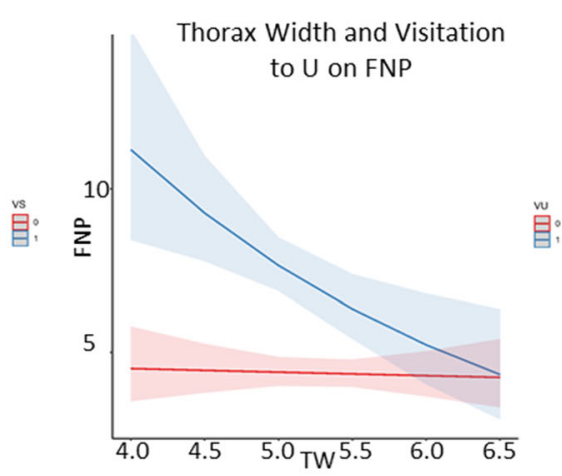

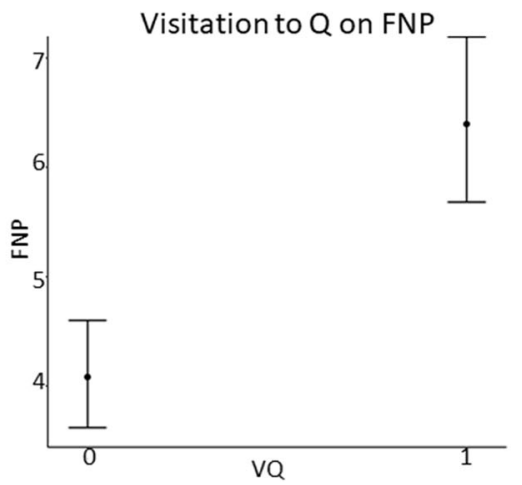

Fig. 3 Marginal effect plots for all terms and interactions in Model 1, the GLM to assess the relationship between flower constancy and foraging location (Table 2). This model found support for Prediction 1 for Question 2, but no support for Prediction 2 for Question 2

indication of possible size-dependent foraging behaviour (e.g. Gervais et al. 2020). The interaction between VS and TW is positive, suggesting that visitation to site $\mathrm{S}$ may have a positive effect on pollen load diversity depending on bee size. Based on the marginal effect plot, we can see that TW has a positive 


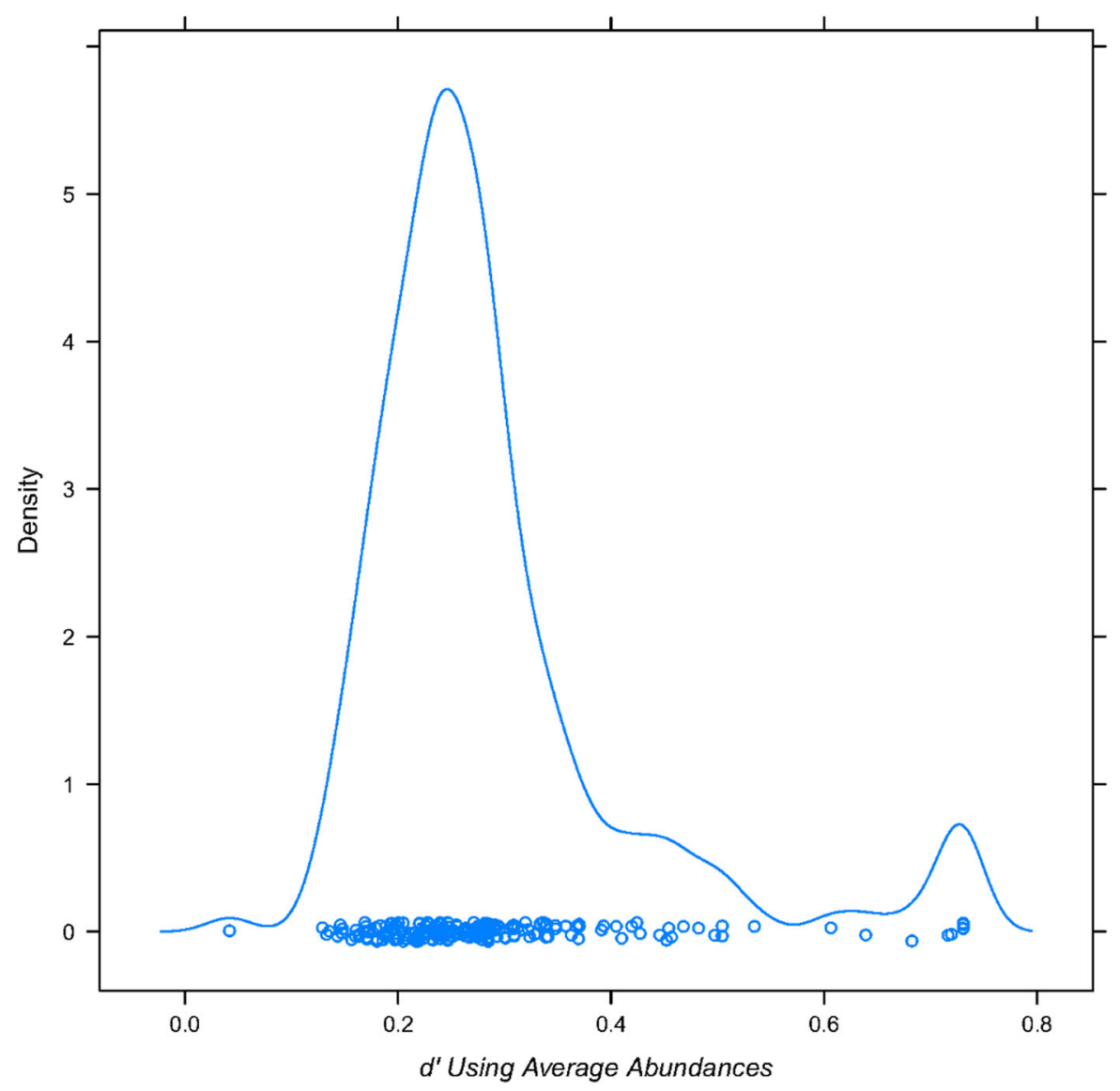

Fig. 4 In the network analysis the mean value for d' was $0.56( \pm 0.116 \mathrm{SD}, \pm 0.008 \mathrm{SE})$ with a slight right skew. Mean d' was significantly different from 0

effect when individuals have visited site $S$, and a negative impact when they have not (Fig. 3). The opposite is true for the interaction between VU and $\mathrm{TW}$, in that when individuals have visited site $\mathrm{U}, \mathrm{TW}$ has a negative impact. When they have not visited site U, TW has no impact (Fig. 3). Also in support of the Prediction for Question 1, in the network analysis the mean value for d' was $0.288( \pm 0.13 \mathrm{SD}, \pm 0.009 \mathrm{SE})$ with a strong right skew (skewness $=1.9$, Fig. 4). This result indicates a high level of flower-inconstant foraging behaviour among the majority of bumblebees sampled. Our mean d' was significantly different from $0(t=42.056$, df $=199, \mathrm{p}<0.05)$, indicating nonrandom visits by the bees among the resource plants.

To address Question 2 Prediction 1, Model 2 tested the number of visits to a site as a function of the number of flowering plant species at that site and the number of foraging stops (Tables 1,2). This model found that the number of recorded visits increases strongly with number of flowering plant species at a site (Fig. 5; R code section 'Visitation vs Richness GLM-replacement for correlation'). We assessed goodness of fit with a Likelihood Ratio Test (LRT) comparing our model to an intercept model with no covariates and found the model including floral richness was the better fit $\left(\mathrm{p}<2.2 \times 10^{-16}\right)$. The number of stops on a foraging trip was dropped from the final model, suggesting there was no significant impact of the number of stops on the number of pollen species in a pollen load, or any significant interaction between the number of stops and the identity of foraging location. Thus, the model result did not provide support for Question 2 Prediction 2. Coefficient estimates, standard error, and $\mathrm{p}$ values are presented in Table 3. 


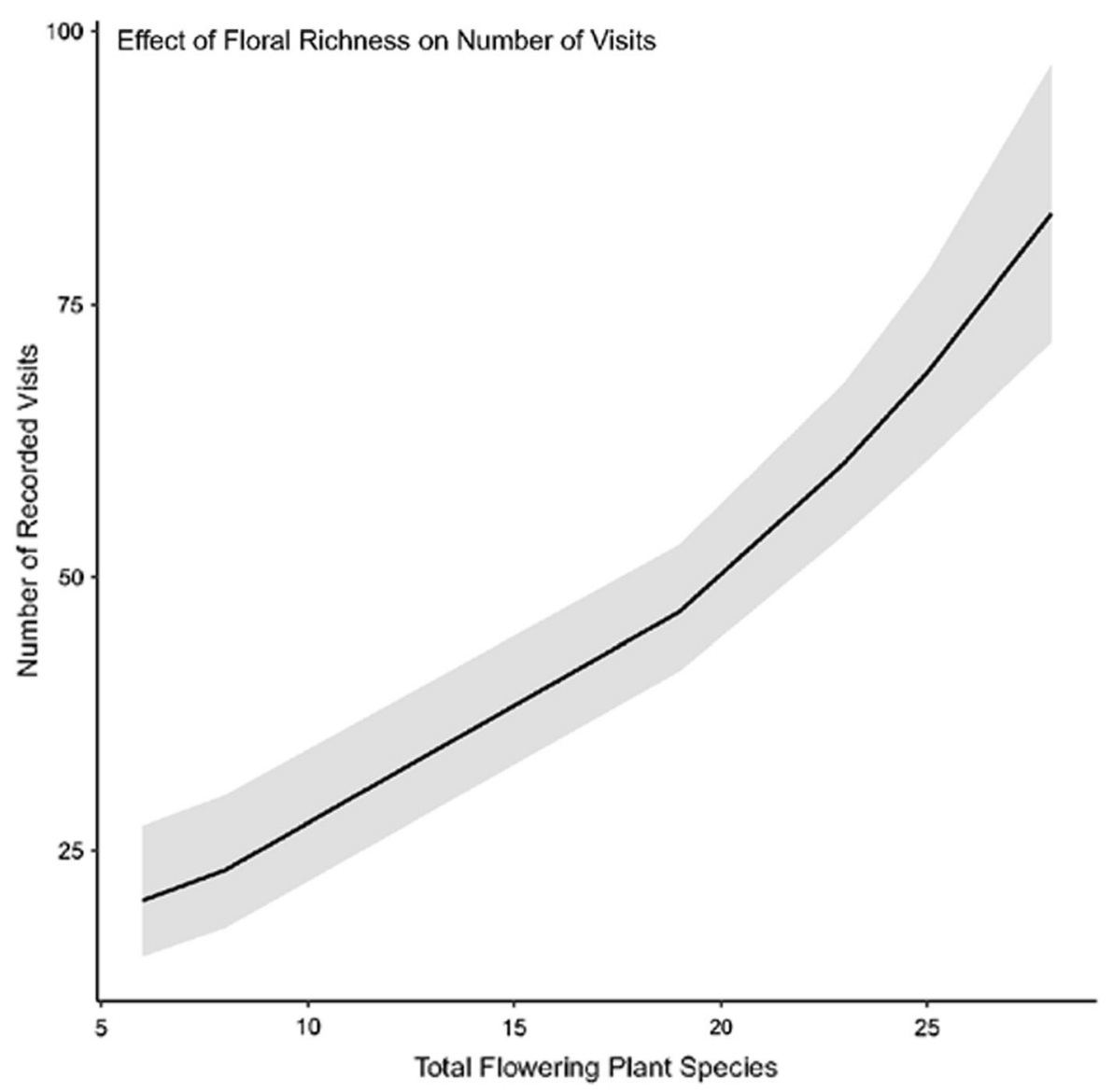

Fig. 5 Results of Model 2, the generalized linear model to test the relationship between number of foraging visits and flower species diversity. In support of Prediction 1 for Question 2, the

Foraging location identification

Of the 200 samples, 115 samples included only one foraging site (57.5\%), 63 included two sites $(31.5 \%)$, 19 included three sites $(9.5 \%)$, and three included four sites $(1.5 \%) .88$ of 200 (44\%) foraging flights were identified as taking place in the 'home meadow'. This included samples that were assigned to the home meadow because they did not contain pigment traces or pollen from single-location species, on the basis that $B$. terrestris workers mainly forage close to the home nest when possible (Wolf and Moritz 2008). Forty-seven of the samples were collected in July before UVPs were applied in the field; of the 153 samples collected in August and September after UVPs were applied, 37 contained UVP traces (24\%), and five of these samples contained two different pigment colours. We tested whether habitat type
GLM found that the number of recorded foraging visits increases strongly with number of flowering plant species at a site

making up the travel path between the two experimental nests, QN and $\mathrm{SN}$, and foraging areas $\mathrm{R}$ or $\mathrm{U}$ (Fig. 1) might be a factor influencing foraging site choice, and found no significant difference between the frequency of crossing the woodland area to visit $\mathrm{U}$ and the frequency of crossing the pasture to visit R (Gtest, $\mathrm{G}=0.11, \mathrm{p}=0.7$ ).

\section{Discussion}

How many flowering plant species are visited by free-flying bumblebees in semi-natural habitats? Is there evidence of floral constancy?

We found that, on average, individual bumblebees visited five different flower species on each foraging trip, and as a group the sampled bumblebees visited 36 
of the 49 flowering plant species present in the study area (Tables S1, S4, S5). Although laboratory experiments with naïve bee foragers, limited floral diversity, and small foraging distances, tend to report high flower constancy (e.g. Heinrich et al. 1977; Gegear and Thomson 2004; Gegear and Laverty 2005; Amaya-Márquez 2009), field observations tend to report low flower constancy and high species diversity in individual pollen loads, similar to that observed in our study (e.g. Free 1970; Chittka et al. 1997; Goulson 1999; Amaya-Márquez 2009; Raine and Chittka 2007; Jha and Kremen 2013). Indeed, reported proportions of field collected pollen loads containing more than one plant species range from 31 to $63 \%$ in bumblebees (Bombus spp.) (Grant 1950; Free 1970; Thomson 1981). Importantly, Grant (1950) found that over half of interspecific flower visits by Bombus spp. resulted in $95 \%$ pure pollen pellets, suggesting that pollen load analysis may result in over-reporting of flower constancy. Previous work has also found that bumblebees, as a colony, often use most of the suitable flowers in bloom at any one time (Heinrich 1976a).

As far as we are aware, there is no specific number of flower taxa an individual must visit, above which the individual would be considered 'inconstant'. Visiting more than one taxa has been considered inconstancy (e.g. Raine et al. 2006), and constancy has also been defined on a spectrum ranging from complete constancy (visiting only a single species) to complete inconstancy (not visiting the same species more than once) (e.g. Bateman's Index, Chittka and Thomson 2001). However, under any definition, estimates of constancy are only meaningful in the context of the available floral resources (see passive constancy, Thompson 1983). Our d' analysis tests the relationship between the species in the pollen load and the species available to be collected, and the results indicate non-random visits by the bees among the resource plants. This result suggests that the high pollen load species diversity we observed is not the result of passive inconstancy, which would be expected to result in similar proportions of species in the field and in the pollen load, but rather an active choice by the bumblebees to forage inconstantly, in line with the energetic costs and benefits hypothesis. In addition, in support of our Prediction for Question 1, our Model 1 results indicate that in more diverse sites pollinators visited more flower species resulting in higher pollen load diversity. Previous authors have also found that higher diversity of floral resources leads to lower floral constancy (Gervais et al. 2020). Following on from our d' result, this low constancy in high diversity sites appears to be the result of 'active inconstancy' rather than passive inconstancy, as in the energetic costs and benefits hypothesis.

Does the number of flowering plant species present in a patch impact the frequency of pollinator visits to the patch, or the number of patches a pollinator visits?

In support of Prediction 1 for Question 2, and in line with the energetic costs and benefits hypothesis, we found that the number of visits to each of the six areas, as estimated by pollen load analysis, was positively correlated with flowering plant diversity. A number of other studies have found a positive relationship between plant species richness and frequency of pollinator foraging visits (references in Hegland and Boeke 2006; Ebeling et al. 2008). There are, however, drivers other than flowering plant diversity or abundance which could influence the probability of visitation to the foraging sites. For example, visitation to the home meadows is also likely to be driven by proximity to the experimental nests. In addition, other studies have observed differences in the probability of pollinators crossing different habitat types (e.g. Lander et al. 2011), or variation in visitation due to landscape context (Klein et al. 2003). However, this study, like Steffan-Dewenter and Tscharntke (1999), found no significant landscape context effect for foraging site selection. We did not find support for Question 2, Prediction 2, which, in line with the costly-information hypothesis, proposed that foraging trips that include the highest floral diversity sites would include fewer total foraging sites than foraging trips that do not include the highest floral diversity sites. Rather, the result of Model 2 suggests that there was little difference between the lower and higher flower diversity sites in terms of how likely foragers were to leave the patch in search of additional foraging sites before returning to the nest.

Comparisons between pollen load species composition and surrounding plant communities are most frequently used to estimate foraging range or to evaluate pollen selection at the colony level, but relationships between floral resource diversity and 
individual pollen load composition have rarely been investigated in the field (Gervais et al. 2020). In addition, the behavioural drivers of the differences between pollen load composition and surrounding vegetation are rarely explored (Gervais et al. 2020). The contribution of this study is to analyse pollen load composition at return to the nest in terms of floral resource availability at the sites visited in the field. The finding that the higher the floral diversity, the higher the pollen diversity in the pollen load, and the positive correlation between site floral diversity and frequency of visitation, suggest behavioural strategies that maximize the diversity of flower species visited, e.g. the energetic costs and benefits hypothesis, at least in field foraging, non-naïve $B$. terrestris.

The novel pollen analogue technique

The novelty of our technique using UV fluorescent pigment as a pollen analogue to identify foraging locations is that across whole meadows all open flowers were marked with a single colour of pigment powder, and thus traces of pigment colour could be used to identify foraging locations. This approach is likely to limit the impact of the pigment application on the experimental results because foragers were only presented with a single pigment colour in any one area, and all open flowers were pigmented, so there were few opportunities for bees to choose between pigment colours or between pigmented and unpigmented flowers.

Thirty-seven of 153 pollen load samples (24\%) collected after UVP application began (5 August, 2015) contained UVPs. Although the UVP method as applied in this study could not be the sole means of identifying bumblebee foraging locations, for 15 of the 37 samples where pigment was visible, it was the only means of identifying foraging location. This means that for $10 \%$ of our samples (15/153), the pollen analogue method provided information on foraging location that would not otherwise have been available, and was a valuable complement to the pollen identification method of identifying foraging locations.

\section{Conclusions and management implications}

The pollen analogue technique, combined with the pollen identification data, provided information on the identity and number of pollen species in the pollen loads, and the identity and number of foraging locations visited by many of the sample bumblebees. The results showed low floral constancy, with individual bumblebees visiting an average of five, and up to 17 , flower species on each foraging trip. In addition, and in accordance with the Prediction for Question 1 and the energetic costs and benefits hypothesis, foragers in the sites with the highest floral diversity displayed the lowest floral constancy. As a group, the foragers made use of 36 of the 49 flowering plant species found in the study area. We also found that, in agreement with Prediction 1 for Question 2 and the energetic costs and benefits hypothesis, flowering plant diversity was positively correlated with foraging site visitation. However, although the bumblebees in this study frequently visited more than one foraging site per foraging bout, we did not find support for Prediction 2 for Question 2, suggesting there was little difference between the lower and higher flower diversity sites in terms of how likely foragers were to leave the patch in search of additional foraging sites before returning to the nest.

The observed low floral constancy behaviour, and the trend for selecting high flower diversity sites, combined with the known nutritional, immunocopetence, and reproductive benefits of polyfloral diets (Vaudo et al. 2015; Roger et al. 2017; Rotheray et al. 2017; Dolezal et al. 2019), all support a recommendation for pollinator plantings with high flower species diversity. We note that the forage value of high diversity planting may be limited by morphological compatibility between foragers and flowers, and that the diversity of flowers may be of greatest benefit to generalist foragers such as the B. terrestris in this study. However, it is also important to note that pollinating insects have frequently been found to be more generalist than initially thought, and have also been shown to be variable in the extent of their specialization depending on environmental variables (Fontaine et al. 2008). This recommendation for high diversity planting could be applied in programs such as the United Kingdom Countryside Stewardship Program, where currently the number of recommended non-grass species per Countryside Stewardship Option ranges from only 4 to $11, \sim \frac{1}{10}$ to $\sim \frac{1}{3}$ of the 36 species the bumblebees visited in this study.

Based on our finding that bumblebees often visited more than one foraging site during a foraging bout, 
land managers interested in pollinator conservation may consider planting many small forage areas across the landscape rather than few large areas. Pollinators with large foraging ranges, such as the $B$. terrestris in this study (Greenleaf et al. 2007), are likely to visit many of the small foraging sites, whereas pollinators with small foraging ranges, such as small solitary bees (Gathmann and Tscharntke 2002), are likely to be within flight range of at least some of the planting sites. Previous authors have similarly suggested that forage availability within flight range of the nest site and across the season may be more important than the spatial continuity of forage resources or the spatial extent of individual patches (e.g. Jha and Kremen 2013; Dicks et al. 2015, 2016; Herascu 2017).

Acknowledgements We thank Nigel Fisher from Wytham Woods for access to field sites and field support, and CEH Wallingford for access to facilities. This project was funded by the Leverhulme Trust and the Eva Crane Trust.

Author contributions TL conceived the field study and collected the field data; TL, FC and $\mathrm{AB}$ conceived the laboratory methods and collected data; TL and AW analysed the data and led the writing of the manuscript. All authors contributed critically to the drafts and gave final approval for publication.

Funding This project was funded by the Leverhulme Trust and the Eva Crane Trust.

Data availability Data will be submitted to the Dryad Digital Repository (https://datadryad.org/) on acceptance of the manuscript.

Code availability $\mathrm{R}$ code for the analyses described in the manuscript are available as Appendix 1 in Supplementary Materials.

\section{Declarations}

Conflict of interest The authors declare that they have no conflict of interest or competing interest.

Consent for publication The authors consent to publication of the manuscript.

Open Access This article is licensed under a Creative Commons Attribution 4.0 International License, which permits use, sharing, adaptation, distribution and reproduction in any medium or format, as long as you give appropriate credit to the original author(s) and the source, provide a link to the Creative Commons licence, and indicate if changes were made. The images or other third party material in this article are included in the article's Creative Commons licence, unless indicated otherwise in a credit line to the material. If material is not included in the article's Creative Commons licence and your intended use is not permitted by statutory regulation or exceeds the permitted use, you will need to obtain permission directly from the copyright holder. To view a copy of this licence, visit http://creativecommons.org/licenses/by/4.0/.

\section{References}

Adler LS, Irwin RE (2006) Comparison of pollen transfer dynamics by multiple floral visitors: experiments with pollen and fluorescent dye. Ann Bot 97:141-150

Amaya-Márquez M (2009) Floral constancy in bees: a revision of theories and a comparison with other pollinators. Revista Colombiana de Entomología 35(2):206

Baselga A, Orme CDL (2012) APPLICATION: betapart: an R package for the study of beta diversity. Methods Ecol Evol 3:808-812

Beil M, Horn H, Schwabe A (2008) Analysis of pollen loads in a wild bee community (Hymenoptera: Apidae) — a method for elucidating habitat use and foraging distances. Apidologie 39:456-467

Blaauw BR, Isaacs R (2014) Larger patches of diverse floral resources increase insect pollinator density, diversity, and their pollination of native wildflowers. Basic Appl Ecol 15(8):701-711

Blüthgen N, Menzel F, Blüthgen N (2006) Measuring specialization in species interaction networks. BMC Ecol. https:// doi.org/10.1186/1472-6785-6-9

Botanical Society of Britain and Ireland, Biological Records Centre, UK Centre for Ecology and Hydrology, Joint Nature Conservation Committee J (Accessed October 2020) Online Atlas of the British and Irish flora. Available from https://www.brc.ac.uk/plantatlas/. Accessed Oct 2020

Calcagno V, de Mazancourt C (2010) glmulti: an r package for easy automated model selection with (generalized) linear models. J Stat Softw 34(12):1-29

Cane J (1987) Estimation of bee size using intertegular span (Apoidea). J Kansas Entomol Soc 60:145-147

Chittka L, Thomson JD (2001) Cognitive ecology of pollination. Cambridge University Press, Cambridge

Chittka L, Gumbert A, Kunze J (1997) Foraging dynamics of bumble bees: correlates of movements within and between plant species. Behav Ecol 8(3):239-249

Chittka L, Thomson JD, Waser NM (1999) Flower constancy, insect psychology, and plant evolution. Naturwissenschaften 86(8):361-377

Csardi G, Nepusz T (2006) The igraph software package for complex network research. InterJ Complex Syst 1695:1

Díaz S, Settele J, Brondízio E (2019) Summary for policymakers of the global assessment report on biodiversity and ecosystem services. Intergouv Sci Policy Platf on Biodivers Ecosyst Servi. https://www.ipbes.net/sites/default/ files/downloads/spm_unedited_advance_for_posting_htn. pdf

Dicks LV, Baude M, Roberts SPM, Phillips J, Green M, Carvell C (2015) How much flower-rich habitat is enough for wild 
pollinators? Answering a key policy question with incomplete knowledge. Ecol Entomol 40(Suppl. 1):22-35

Dicks LV, Viana B, Bommarco R, Brosi B, del Coro Arizmendi M, Cunningham SA, Galetto L, Hill R, Lopes AV, Pires C, Taki H (2016) Ten policies for pollinators. Science 354(6315):975-976

Dolezal AG, Carrillo-Tripp J, Judd TM, Miller WA, Bonning BC, Toth AL (2019) Interacting stressors matter: diet quality and virus infection in honeybee health. R Soc Open Sci 6:181803

Dormann CF, Gruber B, Fruend J (2008) Introducing the bipartite package: analysing ecological networks. R News $8(2): 8-11$

Ebeling A, Klein A-M, Schumacher J, Weisser WW, Tscharntke $\mathrm{T}$ (2008) How does plant richness affect pollinator richness and temporal stability of flower visits? Oikos 117:1808-1815

Fontaine C, Collin CL, Dajoz I (2008) Generalist foraging of pollinators: diet expansion at high density. J Ecol 96(5):1002-1010

Free J (1970) The flower constancy of bumblebees. J Anim Ecol 39:395-402

Gathmann A, Tscharntke T (2002) Foraging ranges of solitary bees. J Anim Ecol 71(5):757-764

Gegear RJ, Laverty TM (2005) Flower constancy in bumblebees: a test of the trait variability hypothesis. Anim Behav 69(4):939-949

Gegear RJ, Thomson JD (2004) Does the flower constancy of bumble bees reflect foraging economics? Ethology 110:793-805

Gemmill-Herren B, Garibaldi LA, Kremen C, Ngo HT (2021) Building effective policies to conserve pollinators: translating knowledge into policy. Curr Opin Insect Sci 46:64-71

Gervais A, Courtois È, Fournier V, Bélisle M (2020) Landscape composition and local floral resources influence foraging behavior but not the size of Bombus impatiens Cresson (Hymenoptera: Apidae) workers. PLoS ONE 15(6):e0234498

Goulson D (1999) Foraging strategies of insects for gathering nectar and pollen, and implications for plant ecology and evolution. Perspect Plant Ecol Evol Syst 2(2):185-209

Goulson D (2009) Bumblebees: behaviour, ecology, and conservation, 2nd edn. Oxford University Press, Oxford

Grant V (1950) The flower constancy of bees. Bot Rev 16(7):379-398

Greenleaf SS, Williams NM, Winfree R, Kremen C (2007) Bee foraging ranges and their relationship to body size. Oecologia 153:589-596

Grüter C, Ratnieks FLW (2011) Flower constancy in insect pollinators: adaptive foraging behaviour or cognitive limitation? Commun Integr Biol 4(6):633-636

Hegland S, Boeke L (2006) Relationships between the density and diversity of floral resources and flower visitor activity in a temperate grassland community. Ecol Entomol 31(5):532-538

Heinrich B (1976a) Bumblebee foraging and the economics of sociality. Am Sci 64(4):384-395

Heinrich B (1976b) The foraging specializations of individual bumblebees. Ecol Monogr 46(2):105-128
Heinrich B, Mudge PR, Deringis PG (1977) Laboratory analysis of flower constancy in foraging bumblebees: Bombus ternarius and B. terricola. Behav Ecol Sociobiol 2:247-265

Herascu R (2017) Bumblebee navigation and foraging behaviour: a short review. Field Stud Counc. http://fsj.fieldstudies-council.org/

Hixon MA (1982) Energy maximizers and time minimizers: theory and reality. Am Nat 119(4):596-599

Jha S, Kremen C (2013) Resource diversity and landscape-level homogeneity drive native bee foraging. Proc Natl Acad Sci USA 110(2):555-558

Johnson JB, Omland KS (2004) Model selection in ecology and evolution. Trends Ecol Evol 19(2):101-108

Kearns CA, Inouye DW (1993) Techniques for pollination biologists. University of Colorado Press, Niwot

Kirby KJ, Smart SM, Black HJ, Bunce RGH, Corney P, Smithers RJ (2005) Long term ecological changes in British woodland (1971-2001). Engl Nat Res Rep 653:1

Klaus F, Bass J, Marholt L, Muller B, Klatt B, Kormann U (2015) Hedgerows have a barrier effect and channel pollinator movement in the agricultural landscape. J Landsc Ecol 8(1):22

Kleiber C, Zeileis A (2008) Applied econometrics with R. Springer-Verlag, New York

Klein AM, Steffan-Dewenter I, Tscharntke T (2003) Fruit set of highland coffee increases with the diversity of pollinating bees. Proc R Soc Lond Ser B 270(1518):955-961

Lander TA, Bebber DP, Choy CTL, Harris SA, Boshier DH (2011) The circe principle explains how resource-rich land can waylay pollinators in fragmented landscapes. Curr Biol 21(15):1302-1307

Lüdecke D (2018) ggeffects: tidy data frames of marginal effects from regression models. J Open Source Softw 3(26):772

Nielsen A, Dauber J, Kunin WE, Lamborn E, Jauker B, Moora M, Potts SG, Reitan T, Roberts S, Sõber V, Settele J (2012) Pollinator community responses to the spatial population structure of wild plants: a pan-European approach. Basic Appl Ecol 13(6):489-499

Oksanen J, Blanchet FG, Friendly M, Kindt R, Legendre P, McGlinn D, Minchin PR, O'Hara RB, Simpson GL, Solymos P, Henry M, Stevens MH, Szoecs E, Wagner H (2017) vegan: community ecology package. R package version 2.4-4. https://CRAN.R-project.org/package=vegan

Ollerton J, Winfree R, Tarrant S (2011) How many flowering plants are pollinated by animals? Oikos 120(3):321-326

Pescott OL, Walker KJ, Jitlal M, Smart SM, Maskell L, Schmucki R, Day J, Amos C, Peck K, Robinson A, Roy DB (2019) JNCC Report No. 622. The National Plant Monitoring Scheme: a technical review. JNCC Peterb.

Pollard E, Yates TJ (1993) Monitoring butterflies for ecology and conservation: the British butterfly monitoring scheme. Chapman \& Hall, London

Potts SG, Biesmeijer JC, Kremen C, Neumann P, Schweiger O, Kunin WE (2010) Global pollinator declines: trends, impacts and drivers. Trends Ecol Evol 25(6):345-353

Powney GD, Carvell C, Edwards M, Morris RK, Roy HE, Woodcock BA, Isaac NJ (2019) Widespread losses of pollinating insects in Britain. Nat Commun 10(1):1018 
Proctor M (2013) Vegetation of Britain and Ireland. Collins, London

Pyke GH (1980) Optimal foraging in bumblebees: calculation of net rate of energy intake and optimal patch choice. Theor Popul Biol 17(2):232-246

Raine NE, Chittka L (2007) Flower constancy and memory dynamics in bumblebees (Hymenoptera: Apidae: Bombus). Entomol Generalis 29(2-4):179-199

Raine NE, Ings C, Dornhaus A, Saleh N, Chittka L (2006) Adaptation, genetic drift, pleiotropy, and history in the evolution of bee foraging behavior. In: Brockmann HJ, Slater PJB, Snowdon CT, Roper TJ, Naguib M, WynneEdwards KE (eds) Advances in the study of behavior. Elsevier, New York, pp 305-354

Roger N, Michez D, Wattiez R, Sheridan C, Vanderplanck M (2017) Diet effects on bumblebee health. J Insect Physiol 96:128-133

Rotheray EL, Osborne JL, Goulson D (2017) Quantifying the food requirements and effects of food stress on bumble bee colony development. J Apic Res 56(3):288-299

Sawyer R (1981) Pollen identification for beekeepers. University College Press, Cardiff

Spaethe J, Weidenmüller A (2002) Size variation and foraging rate in bumblebees (Bombus terrestris). Insectes Soc 49:142-146

Steffan-Dewenter I, Tscharntke T (1999) Effects of habitat isolation on pollinator communities and seed set. Oecologia 121(3):432-440

Thompson JD (1983) Component analysis of community-level interactions in pollination systems. In: Jones CE, Little RJ (eds) Handbook of experimental pollination biology. Van Nostrand Reinhold, New York, pp 451-460
Thomson J (1981) Field measures of flower constancy in bumblebees. Am Midl Nat 105:377-380

Thomson JD, Price MV, Waser NM, Stratton DA (1986) Comparative studies of pollen and fluorescent dye transport by bumble bees visiting Erythronium grandiflorum. Oecologia 69:561-566

R Core Team (2017). R: A language and environment for statistical computing. R Foundation for Statistical Computing, Vienna, Austria. https://www.R-project.org/

Van Rossum F, Stiers I, Geert AV, Triest L, Hardy OJ (2011) Fluorescent dye particles as pollen analogues for measuring pollen dispersal in an insect-pollinated forest herb. Oecologia 165:663-674

Vaudo AD, Tooker JF, Grozinger CM, Patch HM (2015) Bee nutrition and floral resource restoration. Curr Opin Insect Sci 10:133-141

Waddington KD, Holden LR (1979) Optimal foraging: on flower selection by bees. Am Nat 114(2):179-196

Waser N (1986) Flower constancy: definition, cause and measurement. Am Nat 127:593-603

Wolf S, Moritz R (2008) Foraging distance in Bombus terrestris L. (Hymenoptera: Apidae). Apidologie 39:419-427

Wolf LL, Hainsworth FR, Gill FB (1975) Foraging efficiencies and time budgets in nectar-feeding birds. Ecology 56(1):117-128

Publisher's Note Springer Nature remains neutral with regard to jurisdictional claims in published maps and institutional affiliations. 